\title{
Decir lo irrepresentable: hacia un análisis feminista del testimonio de Nieves Ayress Moreno ${ }^{1}$
}

\author{
To say the unrepresentable: \\ towards a feminist analysis of the testimony of Nieves Ayress Moreno \\ Consuelo DíAz Muñoz \\ ${ }^{a}$ Magíster en Arte, Cultura y Pensamiento Latinoamericanos, \\ Instituto de Estudios Avanzados, Universidad de Santiago. \\ $\measuredangle$ consuelodiazm@gmail.com
}

\begin{abstract}
RESUMEN
Este artículo propone un análisis, desde el foco de la teoría feminista, del testimonio de prisión política de Nieves Ayress Moreno durante la dictadura militar chilena. Mediante esta interpretación se pretenden establecer nuevos parámetros para la comprensión y configuración de la mujer en la historia en tanto sujeto político y social activo inserta en un contexto de presidio, violencia y transgresión; de esta forma, se propone que el testimonio permite identificar la formación de un espacio de enunciación válido de un sujeto político no reconocido en su diferencia de género. Así entendido, el testimonio es construido a partir del intercambio de experiencias subjetivas, donde es posible cuestionar, no sólo el rol histórico de la mujer, sino también la capacidad de representación del lenguaje dentro de un tipo de texto que busca relatar la experiencia límite.
\end{abstract}

PALABRAS CLAVE: testimonio, teoría feminista, dictadura militar, prisión política, tortura.

\begin{abstract}
This article proposes an analysis, from the focus of feminist theory, of the testimony of political imprisonment of Nieves Ayress Moreno during the Chilean military dictatorship. Through this interpretation, we intend to establish new parameters for the understanding

1 Este artículo corresponde a un capítulo de una investigación mayor dentro del marco del proyecto "Formas narrativas del testimonio relatos de prisión política en Chile, Argentina, Uruguay y Brasil”. FONDECYT regular $\mathrm{N}^{0} 1161551$.


and configuration of women in history as an active political and social subject inserted in a context of imprisonment, violence and transgression. In this way, it is proposed that the testimony allows identifying the formation of a valid enunciation space of a political subject not recognized in its gender difference. Understood in this way, the testimony is constructed from the exchange of subjective experiences, where it is possible to question, not only the historical role of women, but also the capacity of representation of language within a type of text that seeks to tell the limit experience.

KEY WORDS: testimony, feminist theory, military dictatorship, political prison, torture.

\section{INTRODUCCIÓN}

Sabemos que existen diferentes versiones de la historia (no) oficial dependiendo de quien la enuncie. Desde esta idea, la academia ha intentado cubrir los relatos de aquellos sujetos no reconocidos, de los subalternos, generando estudios poscoloniales o decoloniales, indigenistas, desde la teoría de clases o de raza. Sin embargo, hay al menos un elemento transversal a todos estos focos dignos de analizar: la diferencia de género se presenta como una temática latente para examinar la historicidad de los sujetos sociales que no ha sido del todo abarcada por la academia. Existen estudios elaborados desde la noción de interseccionalidad, es decir, el cruce entre los ejes de género, raza y clase, que sin duda han efectuado un aporte a la complejización del análisis de las problemáticas de los sujetos en posición subalterna. No obstante, lo que interesa en este trabajo es proponer un cruce distinto entre el género y la historia, lo que permitiría ampliar el campo de visión hacia otra arista del problema. Por ello, esta investigación se sitúa en un lugar de análisis interdisciplinario, que transita desde el texto testimonial a la historia reciente de América Latina.

En esta línea, un análisis de los episodios traumáticos de la historia interpretados desde la vivencia y transformaciones de la mujer y la disidencia sexual, brindaría nuevos horizontes de comprensión sobre actores que han sido invisibilizados. En la mayoría de los contextos que construye la oficialidad institucional, se considera que tanto hombres como mujeres han sido torturados, asesinados y desaparecidos, entonces, ¿por qué establecer diferencias? A través de análisis realizados por las mismas víctimas de aquel tipo de torturas sexuales, se concluye que este tipo de violencia de carácter específico no fue visualizada como una práctica basada en un sesgo de género: "[L]as autoridades y las víctimas, no vieron en su momento la especificidad de género de la tortura que se ejerció sobre las víctimas mujeres, ni se cuestionaron que esta especificidad existiera" (Carrera, 2005, p. 58). La tortura es desgarradora e inconmensurable para cualquier cuerpo pero las mujeres, al ser históricamente discriminadas, sufren efectos específicos (Teles, 2015). Es así como las diferencias pueden transformarse en desigualdad. Es por ello que sus relatos permanecen en construcción, pues al narrar los episodios sufridos configura nuevos paradigmas de comprensión. 
En este caso, la inclusión de las mujeres en la historia implicaría "necesariamente la redefinición y ampliación de nociones tradicionales del significado histórico, de modo que abarque la experiencia personal y subjetiva lo mismo que las actividades públicas y políticas" (Scott, 1996, p. 267). Es necesario considerar aquellas vivencias que surgen y contemplan la subjetividad de las actoras, pues también constituyen un relato válido expresado -en este caso- mediante el testimonio. A través de estos se pueden apreciar tanto aquellas otras aristas públicas que contempla la historia como sus sesgos privados, ya que lo personal también es político (Kirkwood, 1986). De esta forma, el presente artículo sostiene como hipótesis que el testimonio de Nieves Ayress permite identificar la formación de un espacio de enunciación válido de un sujeto político no reconocido en su diferencia de género, pues la mujer como sujeto político se reafirma a partir de una autoconsciencia obtenida del intercambio de experiencias subjetivas en un contexto de presidio, violencia y transgresión.

\section{METODOLOGÍA}

En cuanto a la metodología utilizada para analizar este tipo de texto, cabe decir que se considera el planteamiento de la teoría feminista de tal forma que las interpretaciones bajo este foco, no se cuestionen como "verdades subjetivas". Para ello se establece una problemática considerando las experiencias femeninas como un indicador significativo de la "realidad", reconociendo aquella vivencia como un recurso para el análisis social. Es prudente enfatizar que es necesario que las mismas mujeres sean enunciadoras de sus propios discursos para validar las experiencias (Harding, 2002).

Por esta razón el documento a estudiar es el testimonio de Nieves Ayress Moreno, transcrito de una relatoría en un contexto judicial de la Comisión Nacional de Prisión Política y Tortura en el año 2000, pues se trata de una producción directa de la víctima, sin filtros o arreglos editoriales. A partir de ello se permite realizar una lectura detenida (o close reading) de tal forma que se identifiquen los términos lingüísticos con los que la autora se expresa. Mediante este método de lectura es posible enfocarse en pasajes particulares del texto o en su totalidad, para considerar múltiples elementos, ya sean retóricos, estructurales, culturales. Una vez localizados estos factores, se procede a realizar un análisis interpretativo de dichos términos en base a ciertas observaciones planteadas por autoras que trabajan dentro del marco de la teoría feminista: es posible apreciar ciertas particularidades en los relatos producidos por mujeres dentro de un contexto de presidio y violencia, para lo que se han considerado los conceptos de tres investigadoras.

De acuerdo a Jelin (2002) en los testimonios de presas políticas se observa una singular convicción de hablar por un otro ausente que desplaza, incluso, especificidades de la propia vivencia traumática. En el caso de Segato (2003) se cuestionan las múltiples aristas de la violencia y la violación, siendo elementos constantes dentro del presidio político femenino. Transversalmente, se ejecuta un análisis del testimonio desde una perspectiva estructural 
considerando lo propuesto por Kaplan (2002), quien incluye la historia biográfica de Ayress, para entender la memoria y la resistencia política desde una perspectiva de género. Estos tres ejes conceptuales configuran el foco de género desde el cual se analiza el testimonio mencionado para, luego, realizar una reflexión conclusiva respecto a la lectura realizada.

\section{Consideraciones generales para un análisis del testimonio desde la Teoría Feminista}

Es en este punto en particular donde surgen diferentes problematizaciones dentro del ya mencionado contexto de estudios académicos, destacándose una en específico: ¿cómo denominar esta nebulosa respecto al análisis de género? ¿basta con hablar de "género"? ¿o se vuelve necesario vincularse a la teoría feminista? ¿cuáles serían sus diferencias? Para ello hay que tener en consideración lo mencionado por Joan Scott (1996) en El género: una categoría útil para el análisis histórico: el uso de la palabra "género" intenta subrayar la seriedad académica de una obra, porque, en teoría, este concepto sería más neutral y objetivo que "mujeres" o que -como se pretende abordar en esta investigación- "teoría feminista". "El concepto género no comporta una declaración necesaria de desigualdad o de poder, ni nombra al bando (hasta entonces invisible) oprimido" (p. 270), es decir, las mujeres como sujetos históricos válidos serían invisibilizadas bajo una categoría tan general como "género". De acuerdo a esta lógica, es posible preguntar ¿cómo revindicar el análisis teórico feminista en la narrativa de testimonios de prisión política de mujeres desde el uso de "género"? Aquí es donde hay que tener cuidado de no caer en un falso dilema "entre [entender] el feminismo, como opción de militancia, [y e]l "género" como una categoría analítica en los países de América Latina” (Barrig, 1998, p. 9), pues la teoría de género es parte de la teoría feminista, una rama de esta que buscaría "definir las identidades, los roles, los valores, las representaciones o los atributos simbólicos, femeninos y masculinos, como los productos de una socialización de los individuos y no como los efectos de una naturaleza" (Dorlin, 2009, p. 35). La teoría feminista consta de categorías de análisis que permanecen aún en construcción, estableciendo relaciones para complementar y formar un corpus organizado de conceptos y nociones que siguen ciertos cánones. En este caso, se busca plantear aquellas diferencias entre hombres y mujeres como la problemática histórica de una lucha contra la discriminación.

La mujer, en tanto sujeto político, se transforma en una víctima particular de la represión al reconocerse a sí misma como un ser político articulador de múltiples capacidades de agencia. Es así como la represión sufrida por ella reafirmaría sus características de sujeto político, pues al desarticular su rol histórico -doméstico- para asumirse como una ciudadana pluriactiva, desafía el status quo instalado tanto por el Estado como por los organismos represores, lo que trae como consecuencia su particular castigo:

As condições específicas das mulheres, como a gravidez, a maternidade, o parto, o aleitamento materno, o abortamento, a menstruação e até mesmo o fato de serem 
simplesmente mulheres, foram usados, pela repressão política, como mais um recurso para torturar e violentar as mulheres (...) os agentes do Estado ditatorial utilizaram da condição feminina para acirrar todo o proces- so de repressão contra a população, inclusive para executar os sequestros, as torturas e os assassinatos. (Teles, 2015, p. 507)².

Los testimonios de aquellas experiencias pueden funcionar como una instancia en la que es posible apreciar múltiples grados de autoconsciencia, autoreconocimiento y resignificación de sí mismas como sujetos políticos y, por lo tanto, la configuración de un pensamiento feminista.

Desde múltiples focos, la teoría feminista se ocupa del análisis de la construcción de un lazo colectivo y politizado formado por el intercambio de experiencias subjetivas. Considerando esto, una manera interesante de alcanzar concretamente aquellos intercambios de vivencias de este contexto particular es a través de los testimonios de presidio producidos por mujeres en contextos jurídicos y de libre publicación -como revistas, por ejemplo-, tomando en cuenta e interpretando cómo desde su condición de género perciben su situación de violencia y transgresión y cómo, además, este elemento intensifica su proceso de represión por parte de los mecanismos dictatoriales.

Asimismo, es necesario tener presente cómo los actores represivos actúan como una herramienta ejemplificadora y castigadora ante una sujeto que, por parte de los perpetradores, no era reconocida como actor político histórico activo, sino como alguien que pretende escapar del lugar que ocupa en una estructura social preestablecida. Es por esto que se reprimen aquellas características a través de su cuerpo. Las torturas constituidas por diversas violaciones y abusos sexuales poseen una carga didáctico-moralizante, entendiendo estas medidas como actos punitivos en que el perpetrador se concibe como un moralizador. A partir de estas nociones, es posible apreciar cómo aquel particular ensañamiento se traduce en "violencia sexual”, entendiendo este concepto como múltiples tipos de violación, ya que esta se define, de acuerdo a Rita Segato (2003), como cualquier forma de sexo forzado impuesto por un individuo con poder de intimidación sobre otro. Se trata de un acto de manipulación forzada de un cuerpo en el que se desencadena un sentimiento de terror y humillación y, por lo tanto, anulación absoluta que proviene de un acto de poder y sometimiento. Es por esto que la violación debe entenderse

[c]omo castigo o venganza contra una mujer genérica que salió de su lugar, esto es, de su posición subordinada y ostensiblemente tutelada en un sistema de estatus. $Y$ ese abandono de su lugar alude a mostrar los signos de una socialidad y una sexualidad

\footnotetext{
"Las condiciones específicas de las mujeres, como el embarazo, la maternidad, el parto, la lactancia materna, el aborto, la menstruación e incluso el hecho de ser mujeres, simplemente, fueron utilizados por la represión política, como una característica adicional de la tortura y violación de las mujeres (...) los agentes del Estado dictatoriales utilizan la condición femenina para intensificar el proceso de la represión contra la población, incluyendo a ejecutar el secuestro, tortura y asesinato". Traducción de la autora.
} 


\section{DÍAZ}

gobernadas de manera autónoma (...) El mero desplazamiento de la mujer hacia una posición no destinada a ella en la jerarquía del modelo tradicional pone en entredicho la posición del hombre en esa estructura, ya que el estatus es siempre un valor en un sistema de relaciones (p. 31).

En esta serie de transgresiones el uso y abuso del cuerpo del otro sin su consentimiento puede darse de diferentes formas, no todas igualmente observables. Es por ello Segato (2003) define dos tipos de violación: cruenta y metafórica o alegórica. En el caso de la violación cruenta, esta puede entenderse como aquella que comprende penetración, mientras que la alegórica consiste en un contacto no necesariamente sexual, pero en el que sí está plenamente presente la intención de abuso y manipulación indeseada del otro. En este caso, la violación metafórica consideraría todo tipo de humillación y vejámenes perpetuados al otro cuerpo. En todas estas instancias se aprecia el forzamiento, transgresión y humillación del otro, siendo prácticas particularmente dirigidas a quien se aleja de su posición. Así la mujer, al entenderse como sujeto político y manifestarse como tal, significaría -para la estructura social jerarquizada a partir de la diferencia de género- un potencial desplazamiento de la categoría que el hombre ocupa en aquel modelo, particularmente en el de los agentes represivos de la dictadura. Es por esto que la violación sería una forma de restaurar el estatus masculino -genéricamente entendido- dañado.

A partir lo anterior, es posible comprender la particular represión sufrida por las mujeres contrarias a la dictadura durante este periodo: la mujer como sujeto político representaría, entonces, no solo una transgresora ideológica del régimen militar, sino también una amenaza para aquella estructura social concebida. Esto último resulta paradójico, pues, de acuerdo a Forcinito (2003), la patria puede ser entendida como un cuerpo femenino virginal que hay que proteger de cualquier posible penetración de valores externos y perjudiciales; no obstante, la perpetración de los cuerpos femeninos se transforma en una herramienta de control y represión en pos de la protección de la (madre) patria: "[L]a violencia contra los cuerpos que acompañó la representación de la patria como cuerpo femenino virginal a ser protegido, es seguida de políticas de desapariciones" (p. 55). Es por ello que se vuelve imperante restablecer y comprender los vínculos significativos con aquellos cuerpos, de tal forma que sea posible descifrar esta paradoja instalada por las dictaduras. Precisamente, un lineamiento para analizar cómo interactúan estas dicotomías lo constituye la investigación de los testimonios de tortura de mujeres.

Es necesario mencionar que la mujer, en tanto sujeto histórico y político, ha sido capaz de reconocerse como tal a partir de la construcción de un (auto)conocimiento en conjunto, a través del compartir experiencias con sus pares; y, en sus vivencias, notan su agencia pluriactiva: "[L]os objetos de conocimiento son construidos, y no pasivamente registrados (...). [E]l principio de dicha construcción es el sistema de las disposiciones estructurales y estructurantes que se constituyen en la práctica, y que está siempre orientado hacia funciones 
nuevas" (Bourdieu, 2007, p. 85). Es por ello que el sujeto histórico femenino en su calidad de agente es considerado eminentemente como activo y actuante (Bourdieu, 1997), ya que dentro de su construcción y resignificación de objetos de conocimiento, se destaca como principal el entenderse a sí mismas como sujetos pluriactivos y, por lo tanto, como sujetos políticos. Este autoreconocimiento de la mujer como sujeto con alta capacidad de agencia y, por lo tanto, político, es posible identificarlo -por ejemplo- en cómo los movimientos de mujeres reclaman la ampliación de la ciudadanía: "[D]esde la mirada de los subordinados y excluidos, han reclamado la ampliación de la ciudadanía, de la autonomía y de la participación política” (Guzmán \& Bonan, 2006, p. 7).

Los feminismos latinoamericanos presentan un despertar en la época de las dictaduras militares $^{3}$. Ante un escenario doloroso y desolador, ante la represión y el debilitamiento de actores políticos y entidades públicas y estatales, las mujeres comienzan a organizarse para suplir estas falencias. Es importante destacar que este movimiento, en Chile y en Latinoamérica, reacciona tanto al autoritarismo impuesto por la dictadura como al fracaso del proyecto político de izquierda y su incapacidad para incorporar a las mujeres en su utopía revolucionaria (Ríos et al. 2003).

El Estado consideraba a los hombres como los interlocutores privilegiados, estimulando los procesos de individuación de aquellos actores en tanto se reforzaba la asociación de las mujeres en el espacio doméstico. Los hombres accedían a los derechos ciudadanos, principalmente como trabajadores, mientras que las mujeres solo podían lograr derechos a través de su rol doméstico (esposas, amas de casa, madres), es decir, a partir de su relación de dependencia con el hombre (Guzmán \& Bonan, 2006). Estos principios normativos se identifican en los gobiernos anteriores a la dictadura para luego consolidarse durante esta.

Considerando lo anterior, es válido proponer que el feminismo se crea a medida que las mujeres se van entendiendo a sí mismas como sujetos políticos. Dentro de los países del Cono Sur, el feminismo en tanto pensamiento político y movimiento social comenzó a formarse a partir de la propuesta de tomar consciencia de la situación de opresión a la que se enfrentaban las mujeres, problemática que resulta transversal a las clases sociales: "[D] entro de la gama de las relaciones de dominación, la de mayor elaboración teórica es la que se ocupa de las relaciones entre clases antagónicas, y la mujer aparecía, inobjetablemente, repartida en clases sociales" (Kirkwood, 1986, p. 41).

En el caso de Chile, una vez obtenido el derecho a voto (1949), las mujeres debían comenzar a formar parte del nuevo proyecto político social que habría de originarse por la nueva integración de agentes. No obstante, después de este hecho, el movimiento comenzó a debilitarse. Aquello comenzó a cambiar durante los años setenta, la implementación de la

También se le conoce como "segunda ola", ya que los primeros movimientos de mujeres respecto a la lucha por su emancipación fueron las sufragistas durante los años treinta, cuarenta y cincuenta, quienes reclamaban por el derecho a voto y educación. Esta agrupación de mujeres ejecutó una lucha específica por sus derechos ciudadanos, siendo un primer paso en la constitución de las mujeres como sujetos políticos. Este proceso trajo como consecuencia una igualdad formal, no real (Luna, 2001). 
"T" de cobre o DIU como método anticonceptivo durante esa década comenzó a marcar una transformación en la vida de la mujer y sus estándares sociales; asimismo, otro punto potencial de cambio fue la llegada de una propuesta de liberación e igualdad social representada por la Unidad Popular, que buscaba revindicar la participación de los sujetos olvidados por las instituciones: campesinos, trabajadores, mujeres, estudiantes. Dentro de este espacio las mujeres esperaban reivindicarse como actores políticos, pues era el momento óptimo para considerar a las minorías subalternas a nivel institucional gubernamental. No obstante, aquello no ocurrió de tal forma: si bien estas comenzaron su autoreconocimiento como sujetos políticos a través de la valoración de su fuerza laboral que potencia su autonomía y capacidades pluriactivas, su rol permanecía siendo relegado a lo doméstico ante los ojos del Estado y sus instituciones -como la familia-.

La mujer continuaba haciéndose cargo de aquellos espacios, además de encargarse de su actividad política. Las problemáticas que abogaban las feministas quedaban relegadas dentro del discurso político imperante, pues no parecían ser urgentes en comparación a la abrupta diferencia de clases y las consecuencias que ello significaba. Se privilegiaron estas disyuntivas sociales, pues el feminismo no era una necesidad inmediata, no era percibido como una lucha transversal, sino como un paralelo desclasado. Isabel Gannon, socióloga entrevistada en el documental Calles caminadas ${ }^{4}$, menciona aquel ejemplo como un elemento latente de la sociedad:

Cuando yo volví de Estados Unidos, llegué transmitiendo con el cuento del feminismo, cáchate tú cuándo, en 1970, recién salido Allende; todo el mundo me miraba como diciendo, jestai meando fuera de la chata!, no te puedo decir la cara de asco que me pusieron... vendida al imperialismo, con ideas foráneas, qué es esa huevá, tú crees que alguien te va a pescar en eso en este país, tú estás loca. O sea, realmente me tuve que quedar con mi feminismo guardado porque no había hueco, no había espacio, no había nada (2006, p. 163).

Las problemáticas que planteaba el movimiento feminista eran consideradas irrelevantes en contraste con el conflicto de clases. Es por esta razón que Julieta Kirkwood plantea esta lucha como un "Feminismo revolucionario", ya que se instala como un contrapoder en pos de la transformación del sujeto social femenino, propone la apreciación del dominio y la opresión cultural de un sexo sobre otro. Es un problema que engloba la cotidianidad, donde, como decíamos más arriba, lo personal también es político. Por lo tanto, Kirkwood plantea la particularidad revolucionaria del movimiento porque apunta a revertir los conceptos de lo

4 Calles Caminadas (2006) -cuya compilación de entrevistas (2014) fue realizada por Eliana Largo- es un documental que relata la historia del movimiento feminista en Chile desde los años setenta hasta el presente con el primer gobierno de Bachelet. Busca visibilizar el aporte histórico de los procesos reflexivos de las mujeres, contribuyendo al conocimiento y valoración de un movimiento social cuyo pasado y presente se enlaza en un horizonte crítico común. 
netamente femenino, considerando la opresión sexual en un contexto donde solo se valoraba la diferencia de clases, enriqueciendo las nociones de liberación social y política.

El género, al ser una estructura social, construye relaciones desiguales y legitima las diferencias en la participación política (Teles, 2015), lo que podemos ver reflejado de manera más cruda durante la represión en las dictaduras latinoamericanas. De esta forma, la teoría feminista busca analizar cómo esta construcción social, que promueve una manera determinada de ser a partir de un conjunto de identidades específicas de los integrantes de una sociedad, también puede determinar de qué manera los sujetos sociales y políticos se relacionan con la memoria, con el recuerdo, ya que el género, al igual que la memoria, se apoya en construcciones simbólicas generadoras de sentido.

Una instancia operativa y pertinente para analizar los discursos de estas sujetos políticos es el testimonio, pues en este tipo de texto es posible dejar registro de aquellas subjetividades, incluso en contextos limitados -como los judiciales- ya que es a través de la forma y su contenido, lo dicho y lo callado, donde puede descubrirse un discurso, a veces implícito, que da luces sobre sistemas y formas de pensamientos que parecían silenciados. Entonces, ¿cómo interpretar los testimonios de prisión política de las mujeres latinoamericanas en tanto sujetos políticos no reconocidos en su diferencia de género? Esta problemática surge de la lectura del testimonio: cómo abordar, comprender un texto portador de múltiples sentidos que opera mediante diferentes estructuras narrativas (Pizarro, 2017), de tal forma que es capaz de construir un relato capaz de sobreponerse a lo inefable; cómo interpretar una narración que surge de un lugar de enunciación determinado por un contexto de presidio, transgresión y violencia, -estos últimos- no solo por un momento histórico en particular, sino también por la configuración de las relaciones de poder en las que la mujer como sujeto está inmersa de manera subordinada.

Para hablar de testimonio es necesario tener en cuenta que hay variadas formas de comprenderlo. El testimonio no es un simple género híbrido que aúna diferentes matices, sino que se trata de un género omnívoro "que se apropia de distintos subgéneros literarios, de alcance acotado, para generar significaciones asociadas a diferentes matrices de pensamiento" (Pizarro, 2017, p. 23). De esta forma, el testimonio adopta diferentes formas de relatar, construidas desde una imaginación narrativa, constituyéndose como un relato portador de interpretación histórica capaz de servirse de diferentes modalidades de entramados discursivos que dan estructura y significado a una experiencia traumática: “[P] ropongo considerar el testimonio de prisión política y tortura como un texto portador de sentidos, no solo a través de los hechos que narra, sino especialmente de las formas escogidas por quien testimonia para dar un cauce significativo a su experiencia” (p. 23), señala Pizarro. El testimonio cruza la barrera de lo inefable para transformarse en el registro de un discurso con voluntad de interpretación histórica construido a partir de la experiencia que devela las múltiples subjetividades del sujeto femenino; es por ello que el testimonio puede ser entendido como un texto de carácter feminista, pues se construye a partir de vivencias que 
se comparten y problematizan a través de la escritura, de tal forma que la sujeto es capaz de configurarse, comprenderse y (re)significarse en la construcción de su propio relato.

Es en el testimonio donde es posible analizar las aristas que constituyen a esta sujeto político, pues su materialidad textual permite una vía de entrada al referente a través del entramado discursivo que da cuerpo y significado a la vivencia (Pizarro, 2017). Ahora, ¿cómo trabajar esta perspectiva del testimonio de prisión política en el caso de la teoría feminista?, ¿qué problemáticas se presentan en el testimonio de mujeres? Las lecturas feministas de las autobiografías y memorias -por ejemplo- han luchado para definir manifestaciones de las desigualdades de género dentro de estos géneros literarios (Hirsch \& Smith, 2002), pues aún se genera resistencia al momento de hacer diferenciaciones de género entre los testigos y protagonistas.

En las constituciones de las comisiones de verdad y justicia no siempre se consideró una perspectiva de género para abordar las violaciones a los derechos humanos, es decir, en un principio, la represión particular padecida por las mujeres no fue analizada desde aquel punto de vista, sino en conjunto con los demás crímenes. En el caso de Chile, la Comisión Nacional de Verdad y Justicia se forma en 1990 durante el gobierno de la transición de Patricio Aylwin, y ocurre que "el primer intento por determinar la magnitud de dicha violencia se [estrella] con la forma en que se construyeron los archivos en las distintas instituciones, forma que a su vez es producto de las condiciones del discurso social que impidieron que las mujeres denunciaran la tortura" (Carrera, 2005, p. 58). La cercanía temporal de la conformación de la comisión con el golpe de Estado y la actividad de sus simpatizantes y adeptos no permitió un espacio para una formación crítica sobre los padecimientos y horrores creados por la dictadura.

La memoria cultural y de género vinculan un diálogo interdisciplinario entre la teoría feminista y las teorías culturales de la memoria: "Feminist theory can provide a valuable lens

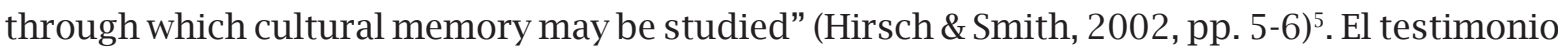
plantea un nuevo lugar de reivindicación, por lo que el análisis teórico feminista sería una herramienta pertinente para tratar las diferentes dimensiones de las relaciones de poder: "[E]l testimonio en tanto narración de la experiencia viva, activa el pensar, y en este sentido, muestra otros mundos posibles que permiten poner en jaque ciertos discursos instaurados con pretensión de verdad" (Ávila, 2015, p. 636). Entonces, ¿̇es posible pensar en procesos de subjetivación a partir de los testimonios de presidio político de las mujeres? El testimonio actúa como un espacio de enunciación válido para un sujeto político histórico no reconocido en tanto su diferencia de género, dando cuenta, precisamente, aquellas subjetividades, pues relata la experiencia del trauma. Los grados de poder o desempoderamiento determinan los espacios que construyen las mujeres y el testimonio deja registro de ello.

La memoria, al ser un problema cultural y político (Sarlo, 2006), destaca la problemática

“La teoría feminista puede proporcionar una lente valiosa a través de la cual se puede estudiar la memoria cultural”. Traducción de la autora. 
de interpretación de aquellos testimonios. Estos, al ser analizados bajo el foco de la teoría feminista, podrían instalarse en un lugar particular de la memoria o conservación. Como señala Todorov, "[l]a memoria no se opone en absoluto al olvido. Los dos términos que se oponen realmente, que forman contraste, son el olvido y la conservación; la memoria es siempre y necesariamente una forma de interacción entre los dos términos” (2013, p. 4). Así, la manera en que conservamos la memoria de la mujer, a través de esta línea interpretativa de sus testimonios, es "una forma de activismo político" (Hirsch \& Smith, 2002, p. 12), siendo el testimonio una pieza clave, pues devela aquellas subjetividades necesarias para la interpretación propuesta. Esto es válido incluso en los casos de los testimonios producidos en contextos judiciales o en las comisiones de verdad, pues, a pesar que se trata de espacios institucionales que funcionan en torno a lo objetivo de las declaraciones, es posible realizar una lectura a partir de lo no dicho. Las palabras escogidas por las testimoniantes jamás son accidentales y los silencios de aquellos discursos también develan verdades: "[e]l tema se refiere al testimonio en sí, los huecos y vacíos que se producen, lo que se puede y lo que no se puede decir, lo que tiene y no tiene sentido, tanto para quien lo cuenta como para quien escucha" (Jelin, 2002, p. 80). Por todo lo anterior, se vuelve necesario realizar una reflexión a partir del análisis de la enunciación y la memoria.

El testimonio de prisión política de mujeres ha sido trabajado mayoritariamente desde el análisis literario e histórico. En este caso, se plantea una lectura bajo este prisma del género y la teoría feminista, considerando el estudio de la enunciación de las torturas sexuales y cómo aquella dimensión sicológica adquiere un carácter de género. Para ello se considera cómo la identidad femenina pasa a entenderse como un objeto sexual en la represión: "Todos los informes existentes sobre la tortura indican que el cuerpo femenino siempre fue un objeto 'especial' para los torturadores. El tratamiento de las mujeres incluía siempre una alta dosis de violencia sexual" (Jelin, 2002, p. 3).

Aquellas características que las instituciones refuerzan en la mujer, como la figura de madre y ama de casa, contenedora de su familia, son las mismas que los aparatos de represión ocuparán para atormentar a las prisioneras. Estos mecanismos constituyen el horror inefable que logra transmitirse mediante el testimonio; los múltiples sentidos que porta este tipo de texto se articulan para construir un discurso significativo de la experiencia traumática:

En el caso de las sobrevivientes, los cuerpos que se juegan en narrar su verdad son cuerpos femeninos que sufrieron golpes, vejaciones, torturas y/o agresiones de tipo sexual. Sin embargo, son también cuerpos resilientes, que reclaman la voz para decir incluso lo indecible. Este posicionamiento (...) acarrea un costo -en tiempo, energía física y psíquica, y a veces, en tener que soportar intimidaciones- A pesar de eso, diversas sobrevivientes también reconocen el valor social del testimonio y el hecho de que puede también resultar beneficioso para quien lo realiza en términos de procesar la experiencia (Sutton, 2014, p. 10). 
Las vivencias traumáticas configuran un discurso complejo de enunciar, es por ello que se observa que "[l]as mujeres sienten vergüenza de hablar de sus experiencias. En testimonios de denuncia (frente a comisiones como testigos en juicios), por ejemplo, informan que fueron violadas, sin dar detalles o describir el hecho" (Jelin, 2002, p. 11). A la luz del análisis del texto de Ayress, será posible identificar como este aspecto no se ve del todo representado en su declaración. El testimonio adopta diversas formas para relatar la experiencia límite -es decir, particularmente, los de prisión política y tortura-, y al ser leídos desde la teoría feminista, es posible apreciar las diferentes dimensiones de las relaciones de poder. Así, el testimonio constituye un nuevo lugar de reivindicación en la historia de la mujer.

\section{Denunciar lo irrepresentable}

El testimonio de Nieves Ayress Moreno (1948), a diferencia de los generalmente estudiados a partir de publicaciones en formato libro, es producido en un contexto judicial, es decir, ella no escribe directamente su relato sino que lo cuenta a una entidad -en este caso el cónsul de Chile en Nueva York, Álvaro Zúñiga- y sus palabras son transcritas por un encargado. Si bien el soporte del testimonio es otro, aún así es posible apreciar las estructuras narrativas que componen un relato oral, considerando que esta constituye una de las formas más antiguas de transmisión de historias.

Nieves Ayress participó desde los veinte años del Ejército de Liberación Nacional de Bolivia, una rama del Partido Socialista en Chile, y en 1973 se unió al Movimiento de Izquierda Revolucionario. Estudiaba Artes y Periodismo en la Universidad de Chile cuando fue detenida y llevada desde la casa de una amiga -quien también se encontraba arrestadaal Estadio Nacional; en esta primera detención, Ayress menciona que también fue víctima de interrogatorios y torturas. Sin embargo, el relato se dedica principalmente a contar lo ocurrido durante su segunda y más extensa detención desde 1974 hasta su exilio en 1976.

Este testimonio está configurado a partir de una estructura concisa y fragmentaria, compuesta por párrafos pequeños de alto contenido. Incluso, esta construcción visualmente tan fracturada puede justificarse en la intensidad de lo relatado, es decir, el uso del punto aparte se vuelve un respiro necesario para continuar avanzando en la narración.

Por otro lado, considerando el contexto de producción de este testimonio, su función se vuelve principalmente pragmática, hay una prioridad práctica tras esta producción ya que el objetivo es denunciar los crímenes contra los derechos humanos en el marco de la Comisión $V_{\text {Valech }}^{6}$. Por esto no se trata de un testimonio cuyo propósito sea retratar los detalles, matices y sensibilidades de una experiencia límite, sino que su función radica en fijar hechos concretos, mantenerse en el marco de lo objetivo y no abrirse a interpretaciones que puedan

\footnotetext{
Comisión Nacional sobre Prisión Política y Tortura creada para investigar a quienes fueron detenidos y torturados durante la dictadura de Pinochet. Esta Comisión fue presidida por el monseñor Sergio Valech, por lo que ahora lleva su nombre como reconocimiento.
} 
desviar la atención de la crudeza de los hechos vivenciados. Así, este testimonio intenta ser lo más neutro posible, de ahí que se desprenda una ausencia de sensibilidad y afectividades pero sí puede apreciarse una constante seguridad de sí misma en la testimoniante de tal manera que ella no se posiciona como una víctima penosa de quien hay que compadecerse, sino que mediante el tono imparcial de su relato es capaz de establecer distancias de tal forma que quien lea o escuche su historia percibirá claramente la crudeza de los hechos.

El contexto jurídico en que se produce el testimonio restringe en ciertos grados las posibilidades del lenguaje, pues debe remitirse a lo objetivo, lo referencial; por lo que cada decisión léxica escogida por quien testimonia se vuelve esencial. Las palabras utilizadas no serían una casualidad, todas estas, incluso los silencios, develan múltiples verdades. Es por ello que se vuelve imperante leer, pensar e interpretar también desde lo no dicho, los huecos y vacíos que se producen en el discurso, lo que se puede y no se puede decir, tanto para quien lo cuenta como para quien lo escucha (Jelin 2002) también configuran la dimensión de lo inefable, característica propia de los hechos traumáticos que se encarga de relatar el testimonio. Así, el silencio deliberado también constituye un indicador sobresaliente y, desde este punto, es posible comprender la característica fragmentaria que construye el testimonio de Ayress, pues está constituido por pequeños párrafos de intensas declaraciones.

De acuerdo a Kaplan (2002) la historia relatada por Ayress la habilita y valida para emplear su memoria desde una perspectiva de género como resistencia política, es decir, las diferentes denuncias dentro de este testimonio pueden ser leídas desde esta línea interpretativa. Para sobrevivir, Ayress Moreno parece haber necesitado comunicar y testificar lo experimentado, y aún lo hace (Kaplan, 2002), es por ello que se dedica a dar entrevistas y reiterar ciertos episodios, ya sea por cuenta propia o dentro del colectivo Mujeres Sobrevivientes Siempre Resistentes ${ }^{7}$. Así como muchas de las testimoniantes cuyo objetivo, además de relatar el horror de lo vivido, también se basa en denunciar a los perpetradores, el caso de Nieves se une a estos propósitos:

Después los carabineros me llevaron al Estadio Nacional, donde estuve presa alrededor de dos semanas, siempre a cargo de carabineros y no de los militares. Estuve dos semanas y empecé a ser torturada. Me tenían en una de las torres del Estadio, sola. Yo veía abajo a los otros presos siendo golpeados y torturados, pero ellos no me veían a mí. A menudo me interrogaban, a golpes y puñetazos, siempre encapuchada. También me insultaban; mis interrogadores tenían acentos brasileros (Ayress, 2000, p. 2).

\footnotetext{
El Colectivo de Mujeres Sobrevivientes Siempre Resistentes fue formado durante diciembre del 2014 con el propósito de visibilizar no solo la violencia de la que fueron víctima las mujeres en dictadura, sino también el carácter sexual de aquellas torturas, asimismo, buscan recuperar diferentes casas de tortura como "La venda sexy" para transformarlas en espacios de memoria. Actualmente participan en diferentes manifestaciones y realizan talleres para estudiantes y para la comunidad, también abogan por una ley que tipifique el delito de violencia política sexual.
} 
En este fragmento en particular, Ayress se posiciona como testigo del sufrimiento de otros, desde su aislamiento en altura es capaz de divisar a presos sin identificación, sin rostro ni nombre particular. Se destaca la mención a que, si bien ella podía observar a los presos, estos no podían verla a ella: ¿cómo considerar la relevancia de este punto? Es posible entenderlo como una invisibilización de una sujeto que también está siendo violentada pero que se le aísla, es ocultada del resto pero permanece como espectadora de la tortura; de ahí que, seguidamente, en su relato mencione que también la interrogaban y golpeaban. Desde la perspectiva postulada por Jelin (2002) sobre cómo las testimoniantes desplazan las propias vivencias en pos de narrar el relato padecido por el otro ausente, se puede apreciar como el relato de Nieve Ayress eclipsa estos recursos, pues es capaz de contar lo que sufren los otros prisioneros, aunque no tenga sus nombres o rostros claros, sin dejar de lado los propios horrores experimentados.

A medida que avanza el relato se evidencian diferentes grados de consciencia tanto de sí misma como de su entorno que, al ser mencionados, constituyen una reafirmación de empoderamiento y autoconsciencia de sí misma como sujeto político, pues es capaz de posicionarse como militante de la resistencia a la par con sus compañeros hombres e, incluso, adelantarse a ciertos hechos:

Me detuvieron nuevamente a mediados de enero del 1974 (...) Entre ellos estaba "El Comandante Alberto, el Esteban”, un hombre que se había infiltrado a varios grupos y movimientos de izquierda. Yo nunca confié en él, pero un compañero del Partido Comunista le había dado mi nombre de guerra y nos habíamos visto, así que él fue el que me identificó cuando me arrestaron (p. 2).

Ayress relata las circunstancias de su segunda y más cruenta detención gracias a un infiltrado en su Partido, por ello considera relevante mencionar que ella nunca confió en él a diferencia de otro de sus compañeros. Para pensar estos aspectos es necesario tener presente lo propuesto por Amar Sánchez (1990) respecto a que el testimonio no se trata, simplemente, de una transcripción de un hecho significativo, pues lo real no es posible describirlo "tal cual es” porque pasa por el lenguaje que actúa como un filtro que configura una realidad propia a partir de la abstracción y organización de los recuerdos. Por esto, aquellos guiños que escapan de lo propiamente referencial dentro de este tipo de relatos enciende ciertas luces del trasfondo desde donde proviene el mensaje, es así como es posible asociar la mención del “yo nunca confié en él” como proyección de sí misma dentro del relato, la reafirmación de su autoconsciencia a nivel político.

Por otro lado, esta idea del lenguaje que limita el relato de lo experimentado puede apreciarse en las decisiones léxicas tomadas por Ayress al momento de narrar las situaciones más violentas de su arresto: “[M]e llevaron al centro de torturas en la calle Londres, donde permanecí alrededor de dos semanas en una celda, sola e incomunicada. Aquí fui torturada 
brutalmente" (2000, p. 3). Previo a la enumeración de las torturas sufridas, la testimoniante califica esta serie de hechos como "brutales", "torturada brutalmente", concepto que sintetiza fielmente lo que expondrá a continuación; y es que el significado de "brutal" retrata el uso de extrema violencia a tal punto que se vuelve irracional. Así, Ayress continúa:

Los métodos de tortura incluían golpes, y choques eléctricos a todas las partes más sensibles del cuerpo, como los senos, los ojos, el ano, la vagina, la nariz, los oídos, y los dedos. También usaban un método de tortura que se llamaba "Pavo de Arara", en el cual me amarraban lo pies y los brazos, me colgaban cabeza abajo, y me aplicaban choque eléctrico al ano. (...) Fui torturada en la presencia de mi padre y hermano, y una vez me forzaron a intentar el acto sexual con mi padre y hermano. Me forzaban a presenciar las torturas de mi padre, de mi hermano, y de otros conocidos que estaban presos. Varias veces en el baño de Londres me violaron (p. 3).

Si bien la magnitud de estos hechos son caracterizados como brutales, el tono referencial del relato se mantiene, no se escapa de los márgenes objetivos incluyendo, por ejemplo, pareceres personales o apreciaciones respecto a lo vivido o sobre sus torturadores, aquellos elementos corresponderían a matices del horror que son silenciados pues responden a lo inefable. Sin embargo, hay un punto muy relevante en el relato de Ayress que no siempre se observa en los demás testimonios sobre represión. Ella menciona cada una de las torturas a las que fue sometida; generalmente, las narraciones de prisioneras no incluyen un panorama tan detallado sobre las transgresiones a las que fueron expuestas, en ocasiones mencionan que fueron violadas o víctimas de abusos sexuales, pero no detallan más sobre las técnicas específicas con las que fueron torturadas (Jelin, 2002). Es decir, el hecho que Ayress especifique las formas de tortura sexual de las que fue víctima significa un quiebre de la clásica forma de relato del testimonio de mujeres, en los que -en su mayoría- la vergüenza por la exposición de estas vivencias, limita los detalles en las declaraciones.

Dentro de esta lógica, Kaplan (2002) también destaca este hecho como una auténtica demostración de valentía: "What is extraordinary about Ayress is not only that she is willing to speak as a woman about the pain and sexual humiliation she suffered at the hands of the military but that she first told her story from prison" (p. 180) ${ }^{8}$. El testimonio de Ayress fue configurado y enunciado desde su estadía en prisión, es decir, sin haber sido liberada ella era capaz de acusar y denunciar los abusos de los que fue víctima.

Las experiencias traumáticas, como ya ha sido mencionado, configuran un discurso complejo de enunciar, en ocasiones inefable. De acuerdo a Rancière (2011) el testimonio también plantea la problemática de lo irrepresentable, pues existe una imposibilidad de

8 "Lo que es extraordinario de Ayress no es solo que ella está dispuesta a hablar, como mujer, sobre el dolor y la humillación sexual sufrida por las manos de los militares, sino que también ella contó, por primera vez, su historia desde la prisión”. Traducción de la autora. 
expresar una vivencia extrema: no habría lenguaje tal para nombrar aquello. Es por esto que el testimonio debe servirse de múltiples estructuras para poder lograr el relato. Desde este punto y tomando en cuenta lo expresado por Nieves Ayress, se vuelve pertinente cuestionar, precisamente, lo inefable del testimonio pues ella es capaz de nombrar una serie de hechos terribles en pos de recomponerse a sí misma como sujeto a través del lenguaje, es por ello que al explicitar los procedimientos de torturas, Ayress permite quebrar con la característica inefable del trauma, pues nombra cada uno de aquellos actos.

Considerando esto, Nieves continúa su testimonio repitiendo la misma fórmula de enumeración de los episodios traumáticos y calificándolos de igual manera: “Tejas Verdes era el lugar donde entrenaban a los militares para ser torturadores, y ahí sufrí torturas brutales. Me forzaban a hacer actos sexuales con un perro que había sido entrenado para participar en torturas" (Ayress, 2000, p. 4). Nuevamente se utiliza el mismo adjetivo calificativo "sufrí torturas brutales", no hay otro concepto que pueda reflejar esta experiencia traumática. Es así como esta decisión léxica se transforma en un ejemplo de los límites del lenguaje en el testimonio y entra en la disputa por lo inefable de este género: ies posible que se trate de una resolución semántica en que el único concepto capaz de abarcar tal magnitud del padecimiento del horror sea, justamente, "brutal", de tal manera que este testimonio continúe desarticulando la característica irrepresentable de las experiencias límites? O bien, ¿se manifiestan las barreras imbatibles del lenguaje que imposibilitan la enunciación de una vivencia traumática en la propia lengua? Por otro lado, al evidenciar el castigo impuesto contra una mujer genérica (Segato, 2003) que desarticula su rol histórico dentro de una dictadura, es posible confirmar cómo se utiliza la condición femenina para intensificar el proceso de represión (Teles, 2015).

Otro ejemplo que delata la problemática de lo inefable es cuando las violaciones no son llamadas por su nombre y se subliman bajo el título de "abusos sexuales": "Los torturadores me violaron en muchas oportunidades, y me tocaban sexualmente, insultándome, y forzándome a tener sexo oral con ellos" (p. 4). Esta distinción entre múltiples violaciones y "tocaciones sexuales" resulta interesante pues ambas contemplan la transgresión y humillación absoluta de un cuerpo, entonces ¿la diferencia radicaría en la ausencia de penetración? De acuerdo a Segato (2013), aquellas tocaciones podrían ser entendidas como una violación alegórica, ya que también se aprecia el forzamiento, la transgresión y el abuso de otro, elementos que son propios de la violación. Ahora, si bien no habría penetración en estas "tocaciones", sí está claramente presente la intención de abuso y manipulación indeseada del otro, en este caso, la violación metafórica consideraría todo tipo de humillación y vejámenes perpetuados al otro cuerpo. Considerando esto, no sería necesario establecer una diferencia entre "tocar sexualmente" y violar, pues ambas constituirían una transgresión con repercusiones traumáticas para esta sujeto. Por otro lado, esta distinción que realiza Ayress revela una importante capacidad de aportar matices, al nombrar lo brutal es capaz de distinguir y demostrar una mentalidad analítica en vez de hablar de "abusos sexuales" a grandes rasgos, 
por ejemplo; es así como cumple la función de brindar un contorno a un referente y, en la voluntad objetiva del testimonio, permite ver lo que nadie quiere saber de la tortura, realizando un juego entre la transparencia y los vacíos del lenguaje.

Como se ha mencionado anteriormente, las mujeres son un sujeto particular dentro de la tortura en dictadura, por ello es necesario considerar cómo la identidad femenina pasa a entenderse como un objeto sexual en la represión y cómo, eventualmente, estas vivencias se plasman en relatos. De acuerdo a Jelin (2002) todos los informes existentes sobre la tortura indican que el cuerpo femenino siempre fue un objeto particular para los torturadores, pues los interrogatorios y tratamientos de las mujeres incluían siempre una alta dosis de violencia sexual. Es en estas instancias donde es posible apreciar cómo no solo las diferencias entre cuerpos de hombres y mujeres, sino los elementos que estructuran estas diversidades sociales, pasan a transformarse en desigualdades: "By reducing women to their bodies, regarding the female body as despicable, and sexualizing the violence against them, army intelligence attempted to transform a woman's identity from political activist to pathetic victim" (Kaplan, 2002, p. 188)9. Las técnicas militares tenían como propósito transformar las identidades de las mujeres militantes políticas en una víctima patética, se buscaba reducir aquellos sujetos políticos a cuerpos despreciables y transgredidos. Mediante la sexualización de las torturas se consideraba posible desarticular su estructura consolidada de sujeto política, pues -en el caso de Nieves- era una herramienta que pretendía marcarla como una mujer vulnerable y, así, removerla del liderazgo.

Es posible entender a la mujer como una sujeto política en tanto es consciente de sus características pluriactivas y su capacidad de agencia, lo que significa que es capaz de desarrollar múltiples roles, no solo dentro del espacio doméstico sino también políticos y organizativos. Así, otro episodio en el que se puede apreciar una reafirmación de Ayress como sujeto política -en tanto se posiciona como víctima de represión debido a su militancia y accionar político e identifica y acusa al culpable de estos hechos- es cuando vincula su experiencia directamente al título de su testimonio “Así me torturó Manuel Contreras" pues es, precisamente, a quien denuncia: "Una vez fui torturada directamente por Manuel Contreras, a quien lo pude divisar porque la venda que cubría mis ojos estaba floja (...) Contreras daba órdenes y supervisaba, pero también participaba directamente en las torturas. En esta sesión, él me golpeó, me dio cachetazos, y me insultó" (Ayress, 2000, p. 4). Pareciera ser una imagen reiterativa la de prisioneras y prisioneros reconociendo a su torturador a través de una venda floja que se desliza para develar rostros ocultos, y este fragmento en particular se encarga de esclarecer las verdaderas funciones del general Contreras, quien en diferentes contextos desmintió que se torturara en los interrogatorios a prisioneros, pues él no solo ejercía el rol de un mandamás sino que también era ejecutor de las múltiples transgresiones que

$9 \quad$ "Al reducir a las mujeres a sus cuerpos, se considera el cuerpo femenino como despreciable y la violencia contra ellos es sexualizada, la inteligencia del ejército intentó transformar la identidad de una mujer activista política en víctima patética". Traducción de la autora. 
sufrieron los detenidos. Por otro lado, la idea de correr la venda también se relaciona a una especie de acceso al nivel de consciencia de la situación, planteando la posibilidad de la anagnórisis ${ }^{10}$ en tanto esta sujeto es capaz de reconocer a quien está en frente a partir de la visión revelada por la caída de la venda.

Un episodio en particular en donde conflictúan los múltiples roles del sujeto femenino es cuando Ayress queda embarazada producto de las numerosas violaciones a las que fue sometida: "En abril me di cuenta que estaba embarazada, y esto lo confirmó el Dr. Mery, un doctor militar que ejercía en la Universidad Católica, y quien me dijo que yo debiera estar orgullosa de tener un "hijo de la patria”" (p. 5). A partir de esta declaración es posible identificar cómo se vincula a la mujer a su clásico rol doméstico, de madre; pues ya han hecho uso de todos los recursos que provee la inteligencia militar para desarticular la politización de esta sujeto, actos que son rematados con la sentencia de sentir orgullo por gestar a un hijo de la patria, es decir, a un crío de un militar violador anónimo, cuyo nombre es desconocido por los lectores y, probablemente, también por Ayress. Es por ello que este anonimato se vierte en la manoseada imagen de la patria que, curiosamente, a veces se le asocia con la idea de mujer, de acuerdo a Forcinito (2003) la patria puede entenderse como un cuerpo femenino virginal que hay que proteger de cualquier posible violación de valores externos y perjudiciales, no obstante, la perpetración de los cuerpos femeninos se transforma en una conocida herramienta de control y represión en pos de la protección de esta "madre patria", de una patria paterna en este caso, que es capaz de engendrar hijos y, así, mantener a la mujer en su lugar legítimo otorgado por los organismos represivos estatales. Esta compleja situación se transforma en transgresora en absolutamente todos los sentidos pues ya no solo se trata de una violación, sino de la gestación de un cuerpo ajeno, por lo que este embarazo se traduce en una constante penetración y abuso del cuerpo femenino. Sin embargo, ante este escenario desolador, Ayress relata:

En Chile el aborto es penado por la ley de cinco años y un día. Yo estaba muy mal físicamente, y si me hacía un aborto clandestino en la prisión me podía morir, y por tal motivo decidí tener el hijo. Después de haber sobrevivido meses de tortura y detención, no les iba a dar el gusto a los militares de morirme. Sin embargo, en abril o mayo, comencé a tener mucho dolor en el vientre, y a perder coágulos de sangre. Aborté en forma espontánea. No recibí atención médica durante el embarazo ni la pérdida (p. 6).

Es posible apreciar claramente una autoafirmación del yo en la medida que la testimoniante es capaz de posicionarse firme dentro de un contexto horroroso: prefiere someterse a una tortuosa gestación del hijo de la dictadura antes que morir, pues aquel acto sería complacer los propósitos de los represores y cumplir lo que esperaban, pues su

10 Poética de Aristóteles. Traducción de Valentín García Yebra. 
muerte significaría el silencio de los múltiples crímenes de los que Ayress fue víctima ${ }^{11}$. De esta forma se puede realizar una lectura pertinente sobre la configuración del sujeto femenino en tanto es autoconsciente de su capacidad de agencia pluariactiva en la medida que es capaz de ejercer diferentes roles. En este caso, Nieves Ayress se instala no solo como una mujer política, sino también como una resistente y como una incubadora generadora de vida, atributo así denominado, ya que resulta imposible nombrarla "madre" en las condiciones de este embarazo.

Son instancias como estas dentro del relato de Ayress, donde es posible distinguir una reafirmación de sí misma como sujeto político, siendo la resistencia un elemento clave, por cuanto refleja el nivel de autoconsciencia de las circunstancias vividas. Desde este punto, Ayress se reconoce como feminista desde pequeña: "When asked about the origins of her feminism, she says she learned it from her mother, who treated all her children equally" (Kaplan, 2002, p.194)12. La testimoniante destaca que el origen de su feminismo radica en su madre, quien trató a sus hijos por igual y se encargó de mostrarle las desigualdades y diferentes roles que ocupa la mujer, pues al ser una familia de origen humilde estas mujeres fueron aguerridas trabajadoras, desarrollando múltiples capacidades que configuran las características que constituyen a un sujeto político, esta serie de elementos alcanzan tal magnitud que incluso dentro del contexto jurídico y funcional que posee este testimonio, es posible apreciar la reafirmación de esta sujeto.

Dentro del pragmatismo con el cual se desarrolla este testimonio, Ayress también es capaz de plantear las consecuencias que aquellos abusos dejaron en su cuerpo y mente, pues estos hechos si bien podrían bordear lo subjetivo, son planteados de forma neutral, sin lamentos o apreciaciones sensibles respecto a lo cruento de sus vivencias:

He tenido muchas secuelas físicas y sicológicas debido a la tortura que sufrí en Chile. Tengo dolor permanente en el cuello, las manos, las rodillas y los pies. Tengo marcas y cicatrices en todo mi cuerpo. Cuando veo una rata, tengo un reflejo de dolor en mi vagina. También tengo un estado de ansiedad constante, y he tenido pesadillas y depresión. He superado algunas de las secuelas sicológicas, por ejemplo, el miedo al encierro que me surgió a causa de las violaciones que sufrí en el baño del centro de torturas de la calle Londres (p. 8).

En este fragmento se pueden destacar dos grandes apreciaciones, por un lado se identifica la memoria del cuerpo al mencionar cómo su órgano reproductivo reacciona ante uno de los elementos que le causaron sufrimiento -una rata que, en este caso, representa

11 "Un grupo de esposas de militares vino a visitarme, y me prometieron la libertad si yo no hacía más declaraciones sobre mi embarazo y mi tortura, y me amenazaron con quitarme mi hijo una vez que naciera" (Ayress, 2000, p. 5). En este fragmento del testimonio se da a entender el afán por silenciar a Nieves, quien continuaba denunciando a diferentes organismos internacionales mientras estaba presa, ella aprovechó cualquier oportunidad que tuvo para contar lo que le había ocurrido.

12 "Cuando se le pregunta por los orígenes de su feminismo, ella dice que lo aprendió de su madre, quien trató a todos sus hijos de igual manera". Traducción de la autora. 
todas las que le fueron introducidas en su vagina-. El cuerpo, al reconocer este animal, reverbera aquellos padecimientos, los efectos del trauma en el cuerpo desencadenan su recuerdo de tal forma que no solo actúan como una secuela física (Stevens, 2017), sino como la reconstrucción de una memoria que excede la mente e inunda el cuerpo.

Por otro lado, el relato de Ayress configura una atmósfera particular para el receptor, pues no habría espacio para experimentar alivio emocional o compasión, considerando que esta contempla un sentimiento de tristeza que busca aliviar o remediar el dolor y sufrimiento de quien lo está padeciendo, ya que no se alcanza a percibir aquella angustia dentro de lo relatado por Ayress, porque la historia que cuenta no se trata de un lamento en búsqueda de empatía, sino de una denuncia que es planteada de forma neutral y, por lo tanto, firme y carente de proyección de este tipo de sentimientos; es por ello que esta información no provee una salida subjetiva emocional para los receptores. Desde este punto, se puede hablar de características "anti catárticas" en este testimonio, recordando que la catarsis se trata de un proceso de purificación mental, corporal y espiritual a partir de la experiencia de compasión y miedo: compadecer a quién sufre y temer por aquella situación cruenta, esta mezcla de sentimientos permitiría una depuración de aquellas pasiones para dar paso a una nueva etapa del receptor ${ }^{13}$. En este caso, tales propósitos no se lograrían ya que la narradora no se plantea como un sujeto a compadecer, no invita a compartir su dolor y terror experimentado, sino que se dedica a acusar aquellos hechos en pos de registrar y justiciar.

Desde este ya mencionado objetivo de denuncia, Nieves Ayress concluye su relato coronando su reafirmación de sujeto a través de una declaración que, sin escaparse plenamente del tono neutral, es capaz de autovalidarse no solo como sujeto político, sino también como sobreviviente y resistente:

Mi familia fue dividida, destruida y toda mi vida cambió después del golpe militar. Pero, al fin, yo estoy aquí, resucitada. Con mi esposo, Víctor Toro, preso y torturado igual que yo, tenemos una hija, Rosita, quien estudia en la Universidad de Nueva York. A los 21 años regresé a Chile con ella, y pude decir a mis torturadores militares: iAquí estoy yo y aquí está mi hija. Me torturaron pero no me destruyeron, no me jodieron porque tuve a mi hija! (2000, p. 8)

Esta última expresión utilizada por la testimoniante puede tener, en parte, una lectura simbólica, pues pareciera plantear la maternidad también como una forma de resistencia, ya que al haber sido fecundada por una violación y, luego, haber perdido aquella gestación producto de las torturas y malos tratos, el hecho de tener nuevamente la posibilidad de ser madre por su propia decisión y medios constituye otra forma de resistencia del cuerpo, es así como Ayress construye un propio panorama de su presente. En primera instancia, se considera como una "resucitada", apelando a una imagen mítico-religiosa que también ha

13 Poética de Aristóteles. Traducción de Valentín García Yebra. 
vuelto a la vida, y es este acto con el que Nieves se siente identificada, no con el calvario y sufrimiento angustioso que lleva a la redención, sino con el hecho de reestablecerse y de reafirmarse. Asimismo, es posible identificar aquella autoconsciencia de los múltiples roles de la mujer en tanto ella asevera haber sido capaz de formar una familia, a pesar de la serie de vivencias cruentas de las que fue víctima, se posiciona y reafirma como una sujeto que no fue desarticulada ni destruida, los organismos represivos no pudieron quebrar aquella identidad de sujeto femenino pluriactivo: su rol político, materno, familiar, organizacional, profesional. Si bien fue perpetrada, abusada y embarazada por la patria represiva, Ayress es capaz de autoposicionarse firme en su discurso, en su declaración y denuncia, demostrando que se mantiene como un sujeto completo, complejo y activo.

Lo particularmente interesante es la última sentencia de este testimonio, por un lado Ayress se instala como una sujeto doble al ligarse a su hija: "Aquí estoy yo y aquí está mi hija”, esta defensa de su maternidad, además de reafirmar sus múltiples roles, puede ser entendida como una garantía de su resurrección, pues intentaron quitarle su vida, destruirla, pero no pudieron hacerlo y no solo eso, sino que también pudo ser capaz de gestar con su propia voluntad un nuevo cuerpo deseado por ella y no impuesto por una serie de violaciones sistemáticas. Por otro lado, la mención de "[m]e torturaron pero no me destruyeron, no me jodieron" proyectaría al menos dos posibles lecturas: el concepto joder se posiciona tanto como un sinónimo de destruir, destrozar, dañar, acciones de las que finalmente no fueron capaces los torturadores; asimismo, la idea de joder remite al acto de violar, penetrar, perpetrar, hechos de los que si bien Ayress fue víctima no lograron transgredir su humanidad, su construcción como sujeto femenino, es por ello que mediante esta última afirmación es posible entender esta reafirmación del yo que postula Nieves Ayress a través de su cruento testimonio.

Ante la neutralidad y temple privado de sensibilidades y afectos de este testimonio, podría insinuarse una suerte de "masculinización" de esta sujeto femenino, pues mantiene un carácter firme y objetivo sin caer en el detalle de sus sentimientos y pasiones, -siendo estas características que, por arraigadas estructuras sociales, se le atribuyen regularmente a los sujetos masculinos-. Sin embargo, esta lectura interpretativa no sería pertinente pues Nieves Ayress Moreno relata las torturas que sufrió desde un autoposicionamiento de mujer, constantemente ella se reconoce y reafirma como una sujeto femenino quien padeció vejámenes y torturas desde y por su cuerpo y roles de mujer, y desde este contexto ella configura su relato sin la necesidad de equiparar su resistencia a la de un hombre o sujeto masculino, sino que constantemente se posiciona en su relato como una mujer que sufrió represión por su elección política, por su activismo, por universitaria; en el fondo, por desconfigurar el clásico rol doméstico al que la mujer estaba relegada tanto por los ideales del Estado consolidados en dictadura, como por sus organismos represivos, siendo así cómo esta mujer debió pagar por su espíritu feminista en tanto sujeto política consciente de su múltiple capacidad de agencia. 


\section{CONCLUSIONES}

De acuerdo al análisis propuesto a lo largo de este artículo, es posible establecer lineamientos dentro del testimonio que funcionan como un registro de la reafirmación y autoconsciencia de la calidad de sujeto político de esta mujer prisionera, pues a medida que realiza un intercambio de experiencias subjetivas a través del testimonio se plantea un reconocimiento de su condición como actora con capacidad de agencia en tanto mujer invalidada por su diferencia de género. A partir de estas observaciones, es posible proponer al menos tres ejes temáticos asociados a cómo es enunciada aquella característica de sujeto político autoconsciente.

En primera instancia, se aprecia un estado de consciencia respecto a su propio género y a su actuar político relegado tanto por los agentes represivos como por los mismos compañeros militantes en la medida que no validaban, completamente, el actuar de la mujer. El rol doméstico propio del género no había logrado ser deconstruido a partir de la vinculación a la militancia política, al contrario, la mujer establecería su politización como otro rol más dentro de sus múltiples actividades. Estos puntos pueden apreciarse en cómo la testimoniante responde a las agresiones de género durante la tortura y presidio, su reacción revela el empoderamiento y afirmación del yo, destacando un pleno estado de consciencia respecto de su propio género y actuar político. Por ejemplo, Ayress hacia el final de su testimonio plantea que aunque hayan destruido a su familia, no pudieron "joderla" pues está viva y tuvo una hija, demostrando una afirmación de sí misma como sujeto que no pudo ser desmantelado por la tortura, destacando su fortaleza y resistencia en tanto mujer que, a pesar de haber sido violada numerosas veces de múltiples formas, pudo engendrar por decisión propia su descendencia.

Otra forma en que se aprecia la enunciación de la mujer como sujeto político autoconsciente es en su capacidad de agencia incluso en situaciones límites. En tanto esta sujeto recurre al testimonio para registrar y denunciar la experiencia cruenta, este texto se va transformando en un proceso de reconocimiento y reafirmación de sí misma y las múltiples operaciones que puede ejecutar desde su posición de mujer. Los diferentes roles de la mujer, es decir, sus capacidades pluriactivas, van evidenciándose en la medida que la narradora construye su historia a través de hechos puntuales: es posible apreciar una agencia latente a través de su resistencia, pues es capaz de ejercer el derecho elemental de cualquier mujer como lo es el decidir sobre el propio cuerpo cuando rechaza la posibilidad de abortar luego de resultar embarazada producto de las múltiples violaciones, pues prefería seguir con vida antes de morir y darle en el gusto a sus torturadores. Este poder de decisión revela no solo un claro empoderamiento de esta sujeto, sino también el nivel de autoconsciencia sobre sus propias capacidades.

Finalmente, gracias a la configuración y estructuración de estos elementos es posible establecer el último punto en torno a cómo el testimonio logra articularse como un espacio 
de enunciación válido para el relato de la experiencia límite de la mujer. Esta instancia permite el procesamiento y replanteamiento de la vivencia, lo que funcionaría como una forma de reafirmación de las sujetos políticos mediante una herramienta textual de carácter testimonial que puede funcionar no solo a modo de registro o discurso con intención histórica sino también como una denuncia de carácter jurídico entre tantas otras formas en que este tipo de texto puede operar. El testimonio, en tanto soporte textual de la vivencia traumática, es capaz de actuar como una instancia pertinente para la afirmación del yo a través del relato. Mediante el planteamiento de las propias subjetividades es posible apreciar el nivel de consciencia de las múltiples capacidades de agencia que, precisamente, configuran la politización de un sujeto femenino.

El testimonio de Nieves Ayress expone sus vivencias a modo de denuncia judicial, construye un relato a partir de estructuras narrativas neutrales y objetivas, siendo necesario desplazar la emocionalidad en pos de un tono serio que actúe como evidencia latente de las violaciones a los derechos humanos ocurridos en periodo de dictadura. Así es como este testimonio al no omitir aquellas marcas que diferencian los géneros en actos tan brutales como la tortura, constituye un potente registro del empoderamiento del sujeto femenino político.

\section{REFERENCIAS}

Aristóteles. Poética. (1974). Trad. Valentín García Yebra. Madrid: Gredos.

Amar, A. (1990). La ficción del testimonio. Revista Iberoamericana, 151, 447- 462.

Ávila, M. (2015). El testimonio y su definición filosófica: producciones de sentido sobre las dictaduras militares del Cono Sur. Revista Kamchatka, 6, 633-649.

Ayress, N. (2000) Testimonio Así me torturó Manuel Contreras en dictadura. Archivo Chile. Santiago. Recuperado de: http://www.archivochile.com/Derechos_humanos/testimo/ hhddtestimo0006.pdf

Barrig, M. (1998). Los malestares del feminismo latinoamericano: una nueva lectura. Latin American Studies Association. Recuperado de: http://americalatinagenera.org/newsite/ images/cdr-documents/publicaciones/igualdadynodiscriminacion/doc_769_LOs_ Malestares_del_Feminismo_Latinoamericano_Barrig.pdf

Bourdieu, P. (1997). Razones prácticas sobre la teoría de la acción. Barcelona: Editorial Anagrama.

Bourdieu, P. (2007). El sentido práctico. Buenos Aires: Siglo veintiuno editores.

Carrera, C. (2005). Un secreto a voces: Violencia sexual como tortura durante la represión política en Chile. Revista Mujer Salud / Red de Salud de las Mujeres Latinoamericanas $y$ del Caribe, 1, 55-67.

Dorlin, E. (2009). Sexo, género y sexualidades: introducción a la teoría feminista. Buenos Aires: Ediciones Nueva Visión. 
Forcinito, A. (2003). Cuerpos y traiciones: violencia doméstica, violencia estatal y derechos humanos. Revista de Investigaciones Literarias y Culturales, 20/21, 51-64.

Guzmán, V., \& Bonan, C. (2006). Feminismos latinoamericanos y sus aportes a la experiencia moderna. En M. M. Errázuriz (Ed.), Saber de ellas: entre lo público y lo privado (pp. 117136). Santiago de Chile: Aguilar.

Harding, S. (2002). ¿Existe un método feminista?. En E. Bartra (Comp.) Debates en torno a una teoría feminista. Ciudad de México: Universidad Nacional Autónoma de México.

Hirsch, M., \& Smith, V. (2002). Feminism and Cultural Memory: An Introduction. Signs, 28(1), 1-19.

Jelin, E. (2002). Los trabajos de la memoria. Madrid: Siglo Veintiuno Editores.

Kaplan, T. (2002). Reversing the Shame and Gendering the Memory”. Signs, 28(1), 179-199.

Kirkwood, J. (1986). Ser política en Chile: las feministas y los partidos. Santiago de Chile: LOM.

Largo, E. (Comp.). (2014). Documental Calles caminadas. Anverso y reverso. Santiago de Chile: Centro de Investigaciones Diego Barros Arana.

Luna, L. (2001). Contextos históricos y discursivos de género y movimientos de mujeres en América Latina. Anuario de Hojas de Warmi, 12, 35-47.

Pizarro, C. (2017). Formas narrativas del testimonio. Milán: Colección Di Segni - Universidad de Milán. En prensa.

Rancière, J. (2011). Si existe lo irrepresentable. En El destino de las imágenes (pp. 119-143). Buenos Aires: Prometeo Libros.

Ríos, M., Godoy, L. y Guerrero, E. (2003). ¿Un nuevo silencio feminista? La transformación de un movimiento social en el Chile posdictadura. Santiago de Chile: CEM/Cuarto Propio.

Sarlo, B. (2006). Tiempo pasado. Cultura de la memoria y giro subjetivo. Una discusión.

México: Siglo XXI.

Scott, J. (1996). El género: una categoría útil para el análisis histórico. En Lamas, Marta (comp.) El género, la construcción social de la diferencia sexual (2013). Ciudad de México: Universidad Nacional Autónoma de México.

Segato, R. (2003). Estructuras elementales de la violencia. Buenos Aires: Universidad Nacional de Quilmes Editorial.

Stevens, D. (2017). Testimonio de prisión política en Chile: una poética de la sobreviviencia. Tesis. Santiago.

Sutton, B. (2015). Terror, testimonio, y transmisión: Voces de mujeres sobrevivientes de centros clandestinos de detención en Argentina (1976-1983). Revista Mora, 21, 5-23.

Teles, Maria Amélia de Almeida. (2015). A construção da memória e da verdade numa perspectiva de gênero. Revista Direito GV, 11(2), 505-522.

Todorov, T. (2013). Los usos de la memoria. En Colección signos de la memoria Museo de la Memoriay Derechos Humanos. Santiago. Disponible en: https://ww3.museodelamemoria. cl/wp-content/uploads/publicaciones/TODOROV/files/assets/basic-html/pagel.html 